IIIIIIIIIIIIIIIIIIIIIIIIIIIIIIIIIIII

Original Article

IIIIIIIIIIIIIIIIIIIIIIIIIIIIIIIIIII

\title{
Sensitivity differences among five species of aquatic fungi and fungus-like organisms for seven fungicides with various modes of action
}

\author{
Takashi NAGAI \\ Institute for Agro-Environmental Sciences, NARO, 3-1-3 Kannondai, Tsukuba, Ibaraki 305-8604, Japan
}

(Received June 19, 2020; Accepted August 30, 2020)

\begin{abstract}
Five species of aquatic fungi and fungus-like organisms were used for toxicity assays with seven fungicides to determine the differences in species sensitivity. A microplate toxicity assay with adenosine triphosphate luminescence detection was used as an efficient and economical high-throughput assay. The obtained toxicity data were standardized based on the species sensitivity distribution method. Species sensitivity differed among the fungicides: Rhizophydium brooksianum was most sensitive to hydroxyisoxazole, isoprothiolane, and ferimzone; Chytriomyces hyalinus was most sensitive to tricyclazole; Sporobolomyces roseus was most sensitive to ipconazole; Aphanomyces stellatus was most sensitive to orysastrobin and kasugamycin. Tetracladium setigerum was not the most sensitive species to any of the tested fungicides. The ranges of $\mathrm{EC}_{50} \mathrm{~s}$ to fungal species were lower than to other aquatic organisms (primary producers, invertebrates, and vertebrates) for hydroxyisoxazole, kasugamycin, isoprothiolane, ipconazole, and ferimzone. These results suggest the usefulness of a battery of fungal species to assess the ecological effects of fungicides.
\end{abstract}

Keywords: aquatic fungi, fungus-like organisms, fungicide, microplate assay, ecological risk assessment.

Electronic supplementary materials: The online version of this article contains supplementary materials (Supplemental Tables S1-S3), which are available at https://www.jstage.jst.go.jp/browse/jpestics/.

\section{Introduction}

Fungi and fungus-like organisms play significant roles in aquatic ecosystems. ${ }^{1)}$ They act as (1) parasites of various organisms (algae, invertebrates, and vertebrates), substantially affecting populations of their host; (2) saprobes, playing an important role in the decomposition of recalcitrant organic materials such as chitin and cellulose; and (3) prey, such as when their zoospores are consumed by predators, facilitating energy transfer from primary producers and detritus to higher, trophic-level organisms. Fungicides are used to control fungal plant pathogens, but they may be highly toxic to aquatic fungi. However, assessment of the ecological effects of pesticides on aquatic ecosystems has usually been conducted by considering toxicity to vertebrates (generally fish), invertebrates (generally arthropods), and primary producers (generally algae and duckweed). ${ }^{2)}$ Thus,

To whom correspondence should be addressed.

E-mail: nagait@affrc.go.jp

Published online October 28, 2020

(c) BY-NC-ND (c) Pesticide Science Society of Japan 2020. This is an open access article distributed under the Creative Commons AttributionNonCommercial-NoDerivatives 4.0 International (CC BY-NC-ND 4.0) License (https://creativecommons.org/licenses/by-nc-nd/4.0/) toxicity to aquatic fungi has been neglected when assessing the ecological effects of fungicides.

Few laboratory bioassay methods have been developed using nontarget fungal species. However, an efficient and ecologically relevant bioassay method using five species of aquatic fungi and fungus-like organisms was developed in our recent study. ${ }^{3)}$ The assay combines a 96-well microplate assay with the determination of biomass via adenosine triphosphate (ATP) luminescence, which is known to be proportional to live cell density. Moreover, the five candidate test species (four fungi and one fungus-like organism, an oomycete) were selected based on their suitability for use in a microplate assay and their ecological relevance: $R h i-$ zophydium brooksianum (Chytridiomycota), Chytriomyces hyalinus (Chytridiomycota), Tetracladium setigerum (Ascomycota), Sporobolomyces roseus (Basidiomycota), and Aphanomyces stellatus (Oomycota).

Sensitivity to herbicides was recently shown to differ remarkably between species of algae, with a clear relationship between species sensitivity and the herbicide mode of action (MoA). ${ }^{4-7)}$ Therefore, the use of only a single representative species for testing would lead to overestimation or underestimation of the ecological risk. However, differences in species sensitivity to fungicides among aquatic fungi and fungus-like organisms are not well understood. The main objective of the present study is to investigate the fungicide toxicity to four species of aquatic fungi 
and one fungus-like organism to assess differences in species sensitivity. For that purpose, toxicity assays were conducted for seven fungicides with various MoAs that are used in Japan.

\section{Materials and Methods}

\section{Test organisms}

The five species used for the toxicity assay were $R$. brooksianum strain NBRC-103829, C. hyalinus strain NBRC-102555, T. setigerum strain NBRC-102389, S. roseus strain NBRC-10566, and A. stellatus strain NBRC-103817. The strains were obtained from the Biological Resource Center, National Institute of Technology and Evaluation, Japan. Stock cultures were maintained using a medium including 2.4 g/L of Potato Dextrose Broth (BD Difco, Franklin Lakes, NJ, USA) and $0.4 \mathrm{~g} / \mathrm{L}$ of Bacto Peptone (BD Difco), the $\mathrm{pH}$ of which was buffered at 7.0 with $500 \mathrm{mg} / \mathrm{L}$ of 3-morpholinopropanesulfonic acid at $20^{\circ} \mathrm{C} .{ }^{3)}$ Routine culture maintenance was performed using both aqueous and solid media with $1.5 \%$ agar.

\section{Toxicity assay using a microplate}

Seven fungicides with various MoAs were used as test substances (Table 1). All analytical standards were purchased from FUJIFILM Wako Pure Chemical Corporation (Osaka, Japan) and used for the toxicity assays and the chemical analysis. The purities of standards were $>99 \%$ except for orysastrobin $(98.8 \%)$. Ferimzone is a $(Z)$-enantiomer that is rapidly metabolized to an $(E)$-enantiomer by light irradiation. The ratio of the two enantiomers in an aqueous environment is approximately $1: 1{ }^{8)}$ therefore, a $1: 1$ mixture of ferimzone enantiomers was used for the toxicity assays. Stock solutions of the fungicides were prepared in dimethyl sulfoxide (DMSO; FUJIFILM Wako Pure Chemical Corporation, Osaka, Japan) except that for kasu-

Table 1. The properties of the seven fungicides studied: Chemical Abstracts Service (CAS) number, mode of action (MoA), and reported pesticide registration criteria in Japan

\begin{tabular}{llcc}
\hline \multicolumn{1}{c}{ Fungicide } & CAS No. & $\mathrm{MoA}^{a)}$ & $\begin{array}{c}\text { Registration } \\
\text { criteria } \\
(\mu \mathrm{g} / \mathrm{L})^{b)}\end{array}$ \\
\hline Hydroxyisoxazole & $10004-44-1$ & $\mathrm{~A} 3$ & 2800 \\
Orysastrobin & $248583-16-1$ & $\mathrm{C} 3$ & 120 \\
Kasugamycin & $19408-46-9$ & $\mathrm{D} 3$ & 6600 \\
Isoprothiolane & $50512-35-1$ & $\mathrm{~F} 2$ & 920 \\
Ipconazole & $125225-28-7$ & $\mathrm{G} 1$ & $150^{c)}$ \\
Tricyclazole & $41814-78-2$ & $\mathrm{I} 1$ & 2100 \\
Ferimzone & $89269-64-7$ & $\mathrm{U}$ & 620 \\
\hline
\end{tabular}

a) FRAC $^{22)}$; A3: DNA/RNA synthesis (proposed); C3: complex III, cytochrome bc1 (ubiquinol oxidase) at Qo site (cyt b gene); D3: protein synthesis (ribosome, initiation step); F2: phospholipid biosynthesis, methyltransferase; G1: C14-demethylase in sterol biosynthesis (erg11/ cyp51); I1: reductase in melanin biosynthesis; $\mathrm{U}$ : unknown mode of action. ${ }^{b)}$ Ministry of Environment. ${ }^{23)}$ c) Registration criteria are not yet developed, therefore a calculated value based on the $\mathrm{EC}_{50}$ for algae, crustacean, and fish (using default uncertainty factors) is shown. The original $\mathrm{EC}_{50}$ values are shown in Supplmental Table S3. gamycin, which was prepared in water because of its high water solubility. The final concentration of DMSO in test solutions was $0.1 \%(\mathrm{v} / \mathrm{v})$, a concentration at which no adverse effects have been observed. ${ }^{3)}$

Toxicity assays were conducted using 96-well microplates according to the previously developed test method. ${ }^{3)}$ Preculturing was performed in $15 \mathrm{~mL}$ of an aqueous medium in borosilicate glass tubes for $72 \mathrm{hr}$ under the same conditions as those for the assay. The precultures were inoculated into the test solutions to give an initial ATP concentration of $10^{-8} \mathrm{M}$, except for $S$. roseus $\left(5 \times 10^{-9} \mathrm{M}\right)$, after filamentous fungal bodies (T. setigerum and $A$. stellatus) were dispersed by sonication. Fungal bodies were grown for $48 \mathrm{hr}$ at $20^{\circ} \mathrm{C}$ in $100 \mu \mathrm{L}$ test solutions in each well of 96-well polystyrene nontransparent white microplates (Falcon, 353296, BD Biosciences, Franklin Lakes, NJ, USA). Test solutions consisted of a culture medium containing a geometric sequence of four to nine concentrations of the test substance with a common ratio of 1.78-3.16 (the number of concentration and the common ratio depended on fungicide and determined by a preliminary test). Each culture experiment, including a control (without test substances or DMSO), was conducted with six replicates.

Fungal biomass was measured by detecting the ATP luminescence at 0 and $48 \mathrm{hr}$ using a microplate reader (Gemini EM, Molecular Devices, San Jose, CA, USA) with the SoftMax Pro Software (Molecular Devices) for analysis. Because measurement of ATP luminescence is destructive, separate culture solutions were used for the measurement at $0 \mathrm{hr}$ (six replicates each for the control experiment). An aliquot of $100 \mu \mathrm{L}$ of reagent for ATP measurement (BacTiter-Glo ${ }^{\mathrm{TM}}$ Microbial Cell Viability Assay, Promega Corporation, Madison, WI, USA) was added to each well just before measurement. This reagent contained luciferin/ luciferase combined with a lysis solution for ATP extraction. ${ }^{9)}$ The relationship between luminescence intensity and ATP concentrations was determined using a standard ATP reagent (AP5107, TOYO B-net, Tokyo, Japan).

In the toxicity test of ipconazole and ferimzone using $S$. roseus, the ATP luminescence tended to increase as the fungicide concentration increased, despite the apparent inhibition of growth that was visually observed ( $S$. roseus is pink). At first, bacterial contamination was suspected, but the results were similar when tested again using cells harvested from a different culture system. Therefore, for comparison, toxicity tests were also performed using transparent microplates with biomass determination via optical density. Fungi were grown for $48 \mathrm{hr}$ at $20^{\circ} \mathrm{C}$ in $200 \mu \mathrm{L}$ test solutions in each well of 96-well polystyrene transparent microplates (Falcon, 351172, BD Biosciences). Fungal biomass was measured as absorbance at $680 \mathrm{~nm}$ with a microplate reader (Model 550, Bio-Rad, Hercules, CA, USA). Other test conditions were the same as above.

\section{Chemical analysis}

At the start $(0 \mathrm{hr})$ and end $(48 \mathrm{hr})$ of the assay, fungicide concentrations in the culture medium were determined. A series of test solutions for chemical analysis were made in a separate 
microplate without fungal inoculation. The microplate was incubated under the same conditions as the other microplates in the growth experiment. Subsamples $(500 \mu \mathrm{L})$ from this microplate were taken at 0 and $48 \mathrm{hr}$, and then an appropriate organic solvent (depending on the fungicides; see sample treatment in Supplemental Table S1) was added. These were stored at $-20^{\circ} \mathrm{C}$ in darkness until analysis. Details of the analytical conditions are shown in Supplemental Table S1. The geometric mean of the fungicide concentrations measured at 0 and $48 \mathrm{hr}$ was calculated. If the geometric mean values were all within $\pm 20 \%$ of the nominal concentration, the concentration-response analysis was conducted using nominal values; otherwise, geometric mean concentrations were used. ${ }^{10)}$

The protocol used here accounts for the physicochemical dissipation of the fungicides, such as that by hydrolysis, adsorption to the test vessel, and volatilization by the same test condition but without fungal inoculation. However, fungi may also be able to degrade fungicides. Here, species sensitivity to a given fungicide is considered to include any degradative ability, given that it is a physiological response to the toxicant.

\section{Concentration-response analysis}

The growth rate $(/ \mathrm{d})$ during the test duration was calculated as follows:

$$
\text { growth rate }=\frac{\ln \left(x_{2}\right)-\ln \left(x_{0}\right)}{2}
$$

where $x_{2}$ and $x_{0}$ are luminescence intensity or absorbance at $2 \mathrm{~d}$ $(48 \mathrm{hr})$ and $0 \mathrm{~d}$, respectively. The average luminescence of the six replicates was used as a unified value of $x_{0}$. The relative growth rates in each test concentration were calculated by dividing the growth rates in each replicate by the average growth rate of the control tests (without fungicides).

Concentration-response functions were determined using statistical regression analysis. The relative growth rates and fungicide concentrations were fitted to a two-parameter log-logit model using nonlinear least squares regression. ${ }^{7)}$ The model can be expressed as follows:

$$
\text { relative growth rate }=\frac{1}{1+\exp \left(f_{\mathrm{a}}+f_{\mathrm{b}} \cdot \ln (C)\right)}
$$

where $C$ is the fungicide concentration (geometric mean or nominal, $\mu \mathrm{g} / \mathrm{L}$ ), and $f_{\mathrm{a}}$ and $f_{\mathrm{b}}$ are coefficient values. The $50 \%$ and $10 \%$ effective concentrations $\left(\mathrm{EC}_{50}\right.$ and $\mathrm{EC}_{10}$, respectively, $\left.\mu \mathrm{g} / \mathrm{L}\right)$ are expressed as follows:

$$
\begin{gathered}
\mathrm{EC}_{50}=\exp \left(-f_{\mathrm{a}} / f_{\mathrm{b}}\right) \\
\mathrm{EC}_{10}=\exp \left(\left[-2.197-f_{\mathrm{a}}\right] / f_{\mathrm{b}}\right)
\end{gathered}
$$

Statistical analyses were conducted using software R ver. 3.4.4 (R Foundation for Statistical Computing). Concentration-response analysis was not conducted when the effect was $<10 \%$ in the tests with the maximum concentration. In this case, the $\mathrm{EC}_{50}$ and $\mathrm{EC}_{10}$ were regarded as greater than the maximum concentration of the test.

\section{Analysis of species sensitivity index}

To compare the difference in species sensitivity among fungicides, the obtained toxicity data were standardized based on the species sensitivity distribution $(\mathrm{SSD})^{11)}$ concept. The standardized toxicity was defined as the species sensitivity index (SSI). ${ }^{6}$ ) Differences in species sensitivity to environmental contaminants can be described by the statistical distribution (often a lognormal distribution), and the SSD has been used as a key concept for higher-tier ecological effect assessment. ${ }^{5)}$

First, SSD analysis was conducted using the $\mathrm{EC}_{50}$ values for five species according to Nagai. ${ }^{5)}$ The 50th percentile value of the analyzed SSD (hazardous concentration for $50 \%$ of the species, $\mathrm{HC}_{50}$ ) was regarded as the standardized toxicity of the fungicide. Then the SSI was calculated as the difference between the $\mathrm{EC}_{50}$ and the $\mathrm{HC}_{50}$ after transformation of the common logarithm:

$$
\mathrm{SSI}=\log _{10} \mathrm{HC}_{50}-\log _{10} \mathrm{EC}_{50}
$$

The SSI is a relative index of the difference in species sensitivity: a higher SSI indicates higher sensitivity, and a difference in SSI of one unit indicates a 10 -fold difference in $\mathrm{EC}_{50}$.

\section{Collection of toxicity data}

Information on the acute effects (defined as a test duration of 1-7 days and endpoint of growth rate for primary producers and immobility/mortality for animals) of pesticides was collected from the available literature. Toxicity data for hydroxyisoxazole, orysastrobin, isoprothiolane, and tricyclazole have been reported previously. ${ }^{5)}$ Toxicity data for kasugamycin, ipconazole, and ferimzone were collected in the present study using the same methods. ${ }^{5)}$

\section{Results}

Thirty-five toxicity tests (seven fungicides $\times$ five species) were conducted, and the raw data (growth rates and nominal, measured, and calculated concentrations) are shown in Supplemental Table S2. The $\mathrm{EC}_{50}$ and $\mathrm{EC}_{10}$ values for each fungicide are shown in Table 2. The toxicity of ipconazole and ferimzone to $S$. roseus could not be detected via the ATP luminescence method (see Materials and Methods), therefore, biomass was measured by absorbance instead. These two toxicity values were determined using the absorbance method (Table 2).

The most sensitive species differed among the fungicides: $R$. brooksianum was most sensitive to hydroxyisoxazole, isoprothiolane, and ferimzone; $C$. hyalinus was most sensitive to tricyclazole; S. roseus was most sensitive to ipconazole; A. stellatus was most sensitive to orysastrobin and kasugamycin.

The SSIs for seven fungicides, based on the $\mathrm{EC}_{50}$ values of the five species, clearly showed differences in species sensitivity among fungicides as uneven pattern of SSI (Fig. 1). The average SSI values for each species ranged from 0.73 for $R$. brooksianum (highest) to -0.34 for $T$. setigerum (lowest), indicating that $R$. 
Table 2. The $50 \%$ and $10 \%$ effective concentrations $\left(\mathrm{EC}_{50}\right.$ and $\left.\mathrm{EC}_{10}, \mu \mathrm{g} / \mathrm{L}\right)$ with $95 \%$ confidence intervals $(\mathrm{CI})$ of each tested species ${ }^{a}$

\begin{tabular}{|c|c|c|c|c|c|}
\hline Fungicide & Species & $\mathrm{EC}_{50}$ & $95 \%$ CI & $\mathrm{EC}_{10}$ & $95 \% \mathrm{CI}$ \\
\hline \multirow[t]{5}{*}{ Hydroxyisoxazole } & R. brooksianum & 5.2 & $3.5-7.6$ & 0.63 & $0.22-1.8$ \\
\hline & C. hyalinus & $>10000$ & - & $>10000$ & - \\
\hline & T. setigerum & $>10000$ & - & $>10000$ & - \\
\hline & S. roseus & $>10000$ & - & $>10000$ & - \\
\hline & A. stellatus & $>10000$ & - & $>10000$ & - \\
\hline \multirow[t]{5}{*}{ Orysastrobin } & R. brooksianum & 1700 & $-^{b)}$ & 1400 & $-^{b)}$ \\
\hline & C. hyalinus & 2300 & $1800-2900$ & 550 & $330-920$ \\
\hline & T. setigerum & 1500 & $940-2400$ & 55 & $15-200$ \\
\hline & S. roseus & 7100 & $6200-8100$ & 1700 & $1300-2200$ \\
\hline & A. stellatus & 810 & $700-950$ & 550 & $410-740$ \\
\hline \multirow[t]{5}{*}{ Kasugamycin } & R. brooksianum & 5400 & $3900-7500$ & 570 & $280-1100$ \\
\hline & C. hyalinus & $>10000$ & - & $>10000$ & - \\
\hline & T. setigerum & $>10000$ & - & $>10000$ & - \\
\hline & S. roseus & $>10000$ & - & $>10000$ & - \\
\hline & A. stellatus & 1900 & $1100-3100$ & 1100 & $270-4900$ \\
\hline \multirow[t]{5}{*}{ Isoprothiolane } & R. brooksianum & 2000 & $1100-4000$ & 980 & $190-5000$ \\
\hline & C. hyalinus & $>10000$ & - & $>10000$ & - \\
\hline & T. setigerum & $>10000$ & - & $>10000$ & - \\
\hline & S. roseus & $>10000$ & - & $>10000$ & - \\
\hline & A. stellatus & $>10000$ & - & $>10000$ & - \\
\hline \multirow[t]{5}{*}{ Ipconazole } & R. brooksianum & 120 & $42-320$ & 1.5 & $0.15-16$ \\
\hline & C. hyalinus & 4200 & $1900-8900$ & 2000 & $670-5800$ \\
\hline & T. setigerum & 840 & $-^{b)}$ & 690 & $-^{b)}$ \\
\hline & S. roseus ${ }^{c)}$ & 39 & $21-69$ & 2.8 & $0.84-9.5$ \\
\hline & A. stellatus & 2700 & $-^{b)}$ & 2100 & $-^{b)}$ \\
\hline \multirow[t]{5}{*}{ Tricyclazole } & R. brooksianum & $>12000$ & - & $>12000$ & - \\
\hline & C. hyalinus & 8700 & $4300-18000$ & 870 & $180-4200$ \\
\hline & T. setigerum & $>12000$ & - & $>12000$ & - \\
\hline & S. roseus & $>12000$ & - & $>12000$ & - \\
\hline & A. stellatus & $>12000$ & - & 7300 & $4600-12000$ \\
\hline \multirow[t]{5}{*}{ Ferimzone } & R. brooksianum & 1400 & $780-2400$ & 530 & $160-1700$ \\
\hline & C. hyalinus & 4800 & $-^{b)}$ & 3800 & $-^{b)}$ \\
\hline & T. setigerum & 12000 & $5900-26000$ & 710 & $240-2100$ \\
\hline & S. roseus ${ }^{c)}$ & 4600 & $3700-5800$ & 850 & $520-1400$ \\
\hline & A. stellatus & 9900 & $-^{b)}$ & 7900 & $-^{b)}$ \\
\hline
\end{tabular}

${ }^{a)}$ Values are reported to two significant digits. ${ }^{b)} \mathrm{CI}$ could not be calculated due to the steep concentration-response relationship. ${ }^{c)}$ Test was conducted using a transparent microplate and optical density was used to determine biomass.

brooksianum is a generally sensitive species.

Differences in species sensitivity among taxonomic groups are shown in Fig. 2. The $\mathrm{EC}_{50}$ values for each species are shown in Supplemental Table S3. For hydroxyisoxazole, kasugamycin, isoprothiolane, ipconazole, and ferimzone, the $\mathrm{EC}_{50}$ ranges were lower for aquatic fungi and fungus-like organisms than for other taxa (primary producers, invertebrates, and vertebrates). On the other hand, for orysastrobin and tricyclazole, the $\mathrm{EC}_{50}$ ranges for aquatic fungi and fungus-like organisms were within those for other species.
The lowest fungal $\mathrm{EC}_{50}$ for each fungicide (Table 2) was compared with the pesticide registration criteria regarding the effect on living environmental animals and plants in Japan (Table 1). The lowest fungal $\mathrm{EC}_{50}$ s were lower than the registration criteria for hydroxyisoxazole (registration criterion: $2800 \mu \mathrm{g} / \mathrm{L}$; lowest $\mathrm{EC}_{50}: 5.2 \mu \mathrm{g} / \mathrm{L}$ ), kasugamycin (registration criterion: $6600 \mu \mathrm{g} / \mathrm{L}$; lowest $\mathrm{EC}_{50}: 1900 \mu \mathrm{g} / \mathrm{L}$ ), and ipconazole (registration criterion: $150 \mu \mathrm{g} / \mathrm{L}$; lowest $\left.\mathrm{EC}_{50}: 39 \mu \mathrm{g} / \mathrm{L}\right)$. For the other four fungicides, the lowest fungal $\mathrm{EC}_{50}$ values were higher than the registration criteria. 


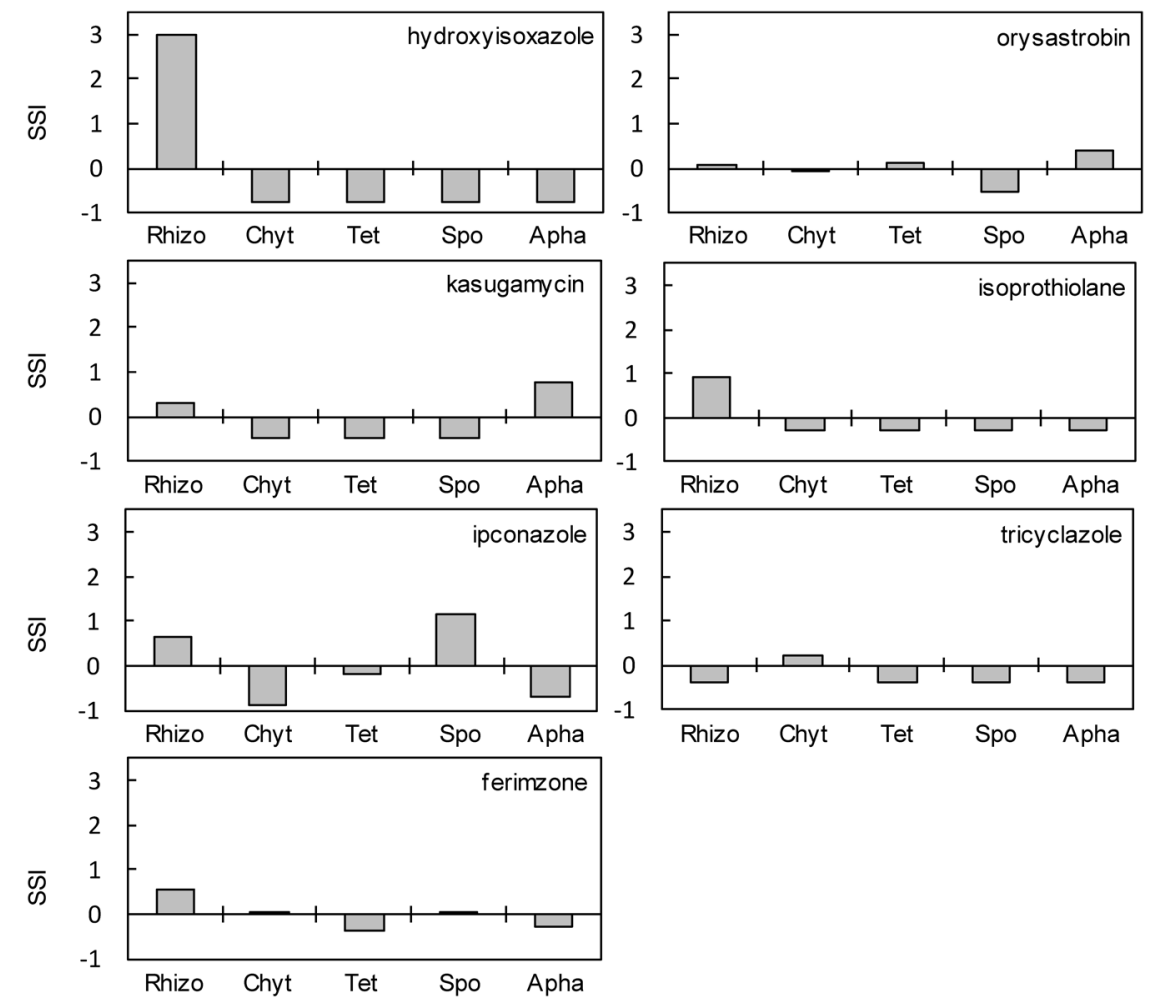

Fig. 1. The SSI for seven fungicides. Rhizo $=$ R. brooksianum, Chyt $=C$. hyalinus, $\mathrm{Tet}=$ T. setigerum, $\mathrm{Spo}=\mathrm{S}$. roseus, Apha $=$ A. stellatus.
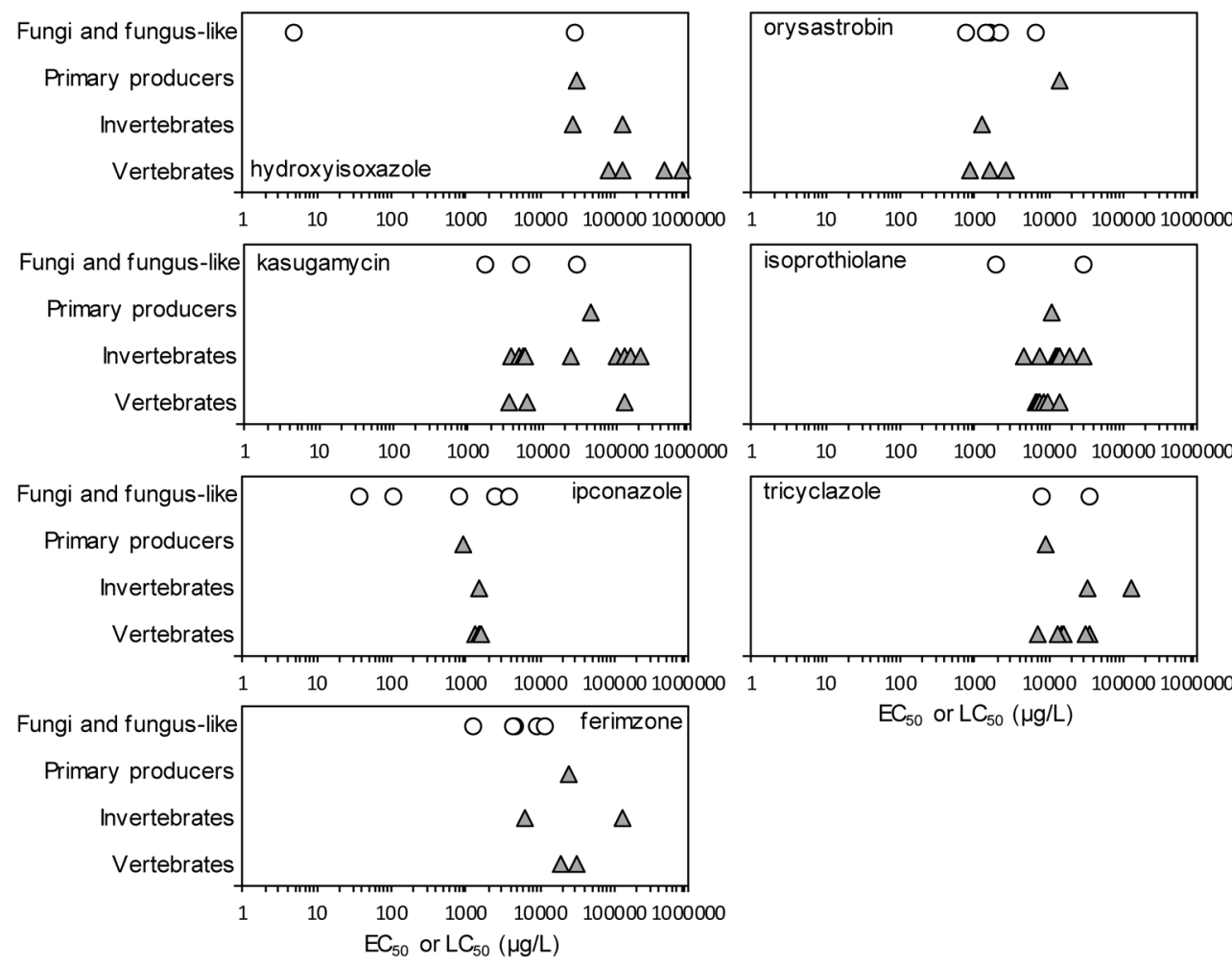

$10 \quad 100 \quad 1000 \quad 100001000001000000$ $\mathrm{EC}_{50}$ or $\mathrm{LC}_{50}(\mu \mathrm{g} / \mathrm{L})$

Fig. 2. $\mathrm{EC}_{50}$ values for aquatic fungi and fungus-like organisms (open circles) and other species (filled triangles). The geometric means of species interval data (e.g., 10,000-100,000 for $\left.\mathrm{EC}_{50}>10,000\right)$ are shown. 


\section{Discussion}

The present study showed the applicability of a fungus microplate toxicity assay to various fungicides. The microplate assay has been widely applied in algal growth inhibition tests. ${ }^{7)}$ The advantages of microplate toxicity assays include (1) a small sample-volume requirement; (2) economy of incubator space; (3) use of disposable microplates; and (4) increased bioanalytical output. ${ }^{12)}$ Moreover, ATP luminescence is easy to measure, is highly sensitive, and is indicator of only viable cells. ${ }^{13)}$ However, a limitation of the method was also found. ATP detection did not work well to test the toxicity of ipconazole and ferimzone to S. roseus, and optical density was used instead. It is not clear why the ATP method did not work well in these cases, but the effects of some fungicides may increase the luminescence of some fungi, which may have been a factor. It should be noted that the results of the toxicity assay for 3,5-dichlorophenol were consistent between methods using ATP luminescence and optical density in the previous paper. ${ }^{3)}$ The effect of fungicides on the luminescence of fungi warrants further study.

The simultaneous assays of five species performed here using the same test medium and culture conditions were better for comparing toxicity data among species. SSI analysis was then applied to the toxicity data collected here to visualize differences in species sensitivity. The seven fungicides, with their various MoAs, showed various SSI patterns (Fig. 1). The most sensitive species differed among fungicides, indicating that a specific species is not always the most sensitive species. Therefore, multispecies toxicity testing is essential to assess the ecological effects of fungicides. These results are consistent with our previous studies using algae ${ }^{14)}$ and primary producers, ${ }^{6)}$ which suggested that variation in species sensitivity greatly depends on the chemical MoA. However, it is necessary to test multiple fungicides with the same MoA to discover the stronger relationship between the difference in species sensitivity and MoA.

Many (but not all) of the fungicides had higher toxicity to aquatic fungi and fungus-like organisms than to other aquatic species (Fig. 2). Although few studies have been conducted on the ecological effects of fungicides on aquatic fungi and funguslike organisms, a few studies have reported a similar conclusion, as described below. Although the fifth percentile of an SSD (5\% hazardous concentration, $\mathrm{HC}_{5}$ ) has been regarded as a safe concentration that protects most species in a community, ${ }^{11)}$ the $\mathrm{HC}_{5}$ values were established using acute toxicity data for aquatic animals and plants, including algae but not fungi. ${ }^{15)}$ Tebuconazole significantly affects the fungal community structure at concentrations lower than $\mathrm{HC}_{5} \cdot{ }^{16,17)}$ Moreover, no observed effect concentrations of nontarget aquatic fungi in laboratory bioassays for epoxiconazole, tebuconazole, and azoxystrobin were lower than their corresponding $\mathrm{HC}_{5}$ values. ${ }^{18)}$ Therefore, it is probable that including the toxicity data of aquatic fungi would markedly change the ecological effect assessment of fungicides.

Although pesticide regulations have yet to be based on ecological risk assessment using fungal toxicity data, this has been suggested as a challenge for the future. The guidance document for risk assessment for plant protection products for aquatic organisms in the European Union ${ }^{19)}$ suggests that further research into potential effects on fungi is needed and that the selection of relevant species for which standardized ecotoxicity tests may be developed should be identified as a research need. Ittner et al. ${ }^{20)}$ reviewed current information on the effects of organic fungicides on freshwater fungi and recommended extending fungicide risk assessment for aquatic organisms to the trophic level of decomposers using selected fungal species as test organisms. Zubrod et al. ${ }^{21)}$ also reviewed current information concerning the ecological risk of fungicides to aquatic organisms and concluded that the fact that current ecological risk assessment protocols ignore fungi is disconcerting and warrants reconsideration, particularly in light of the policy goals, such as the protection of ecosystem services to which they contribute. Therefore, an efficient and ecologically relevant bioassay using aquatic fungi and fungus-like organisms, like those used in the present study, would be useful for the ecological effect assessment of fungicides.

\section{Acknowledgements}

The author thanks Y. Zheng for performing chemical analyses.

\section{References}

1) E. B. G. Jones, K. D. Hyde and K. L. Pang: "Freshwater Fungi and Fungal-Like Organisms," De Gruyter, Berlin, Germany, 2014.

2) MOE: "Setting of Pesticides Registration Criteria Regarding the Effect on Living Environmental Animals and Plants (Initial Report)," Central Environment Council, Japan's Ministry of Environment, Tokyo, 2019 (in Japanese).

3) T. Nagai: Environ. Toxicol. Chem. 37, 1980-1989 (2018).

4) T. Nagai and K. Taya: Environ. Toxicol. Chem. 34, 677-684 (2015).

5) T. Nagai: J. Pestic. Sci. 41, 6-14 (2016).

6) T. Nagai: Jpn. J. Environ. Toxicol. 19, 83-91 (2016) (in Japanese with English abstract).

7) T. Nagai, K. Taya and I. Yoda: Environ. Toxicol. Chem. 35, 368-375 (2016).

8) Food Safety Commission of Japan: "Risk Assessment Report of Ferimzone, Version 2," Food Safety Commission of Japan, Tokyo, 2012 (in Japanese).

9) L. M. Junker and J. Clardy: Antimicrob. Agents Chemother. 51, 35823590 (2007).

10) OECD: "Guidelines for the Testing of Chemicals, Guideline 201Freshwater Alga and Cyanobacteria Growth Inhibition Test," Organization for Economic Cooperation and Development, 2011.

11) L. Posthuma, G. W. Suter and T. P. Traas (eds.): "Species Sensitivity Distributions in Ecotoxicology (Environmental and Ecological Risk Assessment)," Lewis Publisher, Boca Raton, USA, 2001.

12) C. Blaise and P. Vasseur: "Algal Microplate Toxicity Test," eds. by C. Blaise and J. F. Ferard, Small-Scale Freshwater Toxicity Investigations, Vol. 1: Toxicity Test Methods, Springer, Dordrecht, Netherlands, pp. 137-180, 2005.

13) M. Balouiri, M. Sadiki and S. K. Ibnsouda: J. Pharm. Anal. 6, 71-79 (2016).

14) T. Nagai: J. Pestic. Sci. 44, 6-14 (2019).

15) L. Maltby, T. C. M. Brock and P. J. van den Brink: Environ. Sci. Tech- 
nol. 43, 7556-7563 (2009).

16) M. Bundschuh, J. P. Zubrod, S. Kosol, L. Maltby, C. Stang, L. Duester and R. Schulz: Aquat. Toxicol. 104, 32-37 (2011).

17) M. R. Dimitrov, S. Kosol, H. Smidt, L. Buijse, P. J. van den Brink, R. P. A. van Wijngaarden, T. C. M. Brock and L. Maltby: Sci. Total Environ. 490, 1002-1011 (2014).

18) J. Dijksterhuis, T. van Doorn, R. Samson and J. Postma: Water Air Soil Pollut. 222, 421-425 (2011).

19) A. Aagaard, T. Brock, E. Capri, S. Duquesne, M. Filipic, A. F. Hernandez-Jerez, K. I. Hirsch-Ernst, S. H. Bennekou, M. Klein, T. Kuhl, et al.: EFSA J. 11, 3290 (2013).

20) L. D. Ittner, M. Junghans and I. Werner: Front. Environ. Sci. 6, 105 (2018).
21) J. P. Zubrod, M. Bundschuh, G. Arts, C. A. Brühl, G. Imfeld, A. Knäbel, S. Payraudeau, J. J. Rasmussen, J. Rohr, A. Scharmüller, K. Smalling, S. Stehle, R. Schulz and R. B. Schäfer: Environ. Sci. Technol. 53, 3347-3365 (2019).

22) FRAC: "FRAC Code List ${ }^{\odot}$ 2020: Fungal Control Agents Sorted by Cross Resistance Pattern and Mode of Action," Fungicide Resistance Action Committee. https://www.frac.info/docs/default-source/ publications/frac-code-list/frac-code-list-2020-final.pdf?sfvrsn = 8301499a_2 (Accessed in April, 2020).

23) MOE: "Assessment Report of the Pesticide Registration Criteria Concerning Toxicity to Aquatic Organisms," Japan's Ministry of Environment, Tokyo (in Japanese). http://www.env.go.jp/water/sui-kaitei/ kijun.html (Accessed in April 2020). 